\title{
Patterns of Upper Aero-digestive Tract Cancers in Kamrup Urban District of Assam: A Retrospective Study
}

\author{
Jagannath Dev Sharma ${ }^{1}$, Manoj Kalita ${ }^{1 *}$, Debanjana Barman ${ }^{1}$,Arpita Sharma ${ }^{1}$, \\ Ranjan Lahon ${ }^{1}$, Jamil Ahmed Barbhuiya ${ }^{1}$, Barsha Deka ${ }^{1}$, Amal Chandra Kataki ${ }^{2}$
}

\begin{abstract}
Background: The incidence of upper aero-digestive tract (UADT) cancers, including C00-C14, C30-C32, C15 and C16, is increasing rapidly in Kamrup Urban District (KUD) of Assam, North East (NE) India. According to the NCRP (2013) report $37.6 \%$ of all cancers in both sexes are UADT cancers in the NE region, accounting for $53.3 \%$ in males and about $27.5 \%$ in females of the total cases Materials and Methods: A retrospective study was conducted for patient information from the period of 2008-2011. Age-standardized or age-adjusted rates (ASR or AAR) (per 100,000 person-years) were calculated using the World Standard Population as proposed by Segi and modified by Doll et al. The registry population area at risk was estimated using the 1991 and 2001 census population by sex, as well as the growth rate during that interval using the difference distribution method. Results: There were 5,638 cases registered during the last four years of the study (2008-2011) accounting for $56.7 \%(3,198 / 5,638)$ of the total in males and $43.3 \%(2,440 / 5,638)$ in females. The male: female ratio was 1.31 : 1.00. The overall age adjusted rates (AAR) were 179.4 and 153.8 per 100000 males and females respectively. Cancer of the oesophagus was most common in both sexes, with most appreciable gender variation for tongue and hypopharynx, presumably reflecting differential expsoure to risk factors.
\end{abstract}

Keywords: Upper aero-digestive tract cancer - AAR - risk factors - Kamrup Urban District - Assam - India

Asian Pac J Cancer Prev, 15 (17), 7267-7270

\section{Introduction}

The incidence of upper aero-digestive tract (UADT) cancers were increasing rapidly in Kamrup Urban District (KUD) of North East (NE) India. The Upper Aero-Digestive Tract (UADT) cancer groups consist of C00-C14, C30-C32, C15 and C16 (NCRP 2013; Sharpe et al., 2014). The carcinomas of oral cavity and pharynx are the common sites and contributed nearly about 400 , 000 incidence cases for each year globally and half of that occurred in India. Globally nearly 200,000 die of the disease, and more than one third deaths occurred in India (Anantharaman et al., 2014). In the year 2008 globally an estimated of 482,300 new esophageal cancer cases and 406,800 deaths had occurred (Jemal et al., 2011) In India an estimated of 42513 esophageal cancer cases burden will be for the year 2020 (Takair et al., 2010) and globally a total of 989,600 new stomach cancer cases and 738,000 deaths are estimated to have occurred in 2008, accounting for $8 \%$ of the total cases and $10 \%$ of total deaths (Jemal et al., 2011). Consumption of alcohol, smoking, smokeless tobacco, chewing habits of betel nut with or without tobacco and some of the ethnical food \& dietary habits are most common risk factors of UADT cancers (Oze et al., 2009; Sharma et al., 2013).

The recent three year report (2009-2011) published by National Cancer Registry Programme (NCRP, 2013) reported that incidence of UADT cancers in North-East (NE) region of India is at rise and for some of the sites they shows highest incidence rates globally. According to the report $37.6 \%$ of all cancers in both sexes are of UADT cancers in NE region (NCRP 2013). UADT cancers comprised of $53.3 \%$ in males and near about $27.5 \%$ in females to the total cases reported from NE India as well as from Kamrup Urban District (KUD) of Assam, India.

The objective of the study was to provide an overall view of Upper Aero-Digestive Tract (UADT) cancer groups of KUD to set priorities for cancer control measures.

\section{Materials and Methods}

A retrospective study was done for the patients information from the period of 2008-2011. PBCR Guwahati covers kamrup urban District of Assam, India which comprises a total area of $261.8 \mathrm{sq} \mathrm{km}$ with a total population of 900,518 (male 490,772, female 409,746) as according to 2001 census (Sharma et al., 2013). 
Table 1. Age Specific Incidence Rates, Age-standaridzed Incidence Rates (AARs) and Average Annual Crude Incidence Rates (CRs) by Site Among Males in the Kamrup Urban District, 2008-2011

\begin{tabular}{|c|c|c|c|c|c|c|c|c|c|c|c|c|c|c|c|c|c|c|c|c|}
\hline \multirow[t]{2}{*}{ ICD-10 } & \multirow[t]{2}{*}{ Sites } & \multirow[t]{2}{*}{ Total } & \multicolumn{18}{|c|}{ Age (years) } \\
\hline & & & 00-04 & $5-9$ & $10-14$ & $15-19$ & $20-24$ & $25-29$ & $30-34$ & $35-39$ & $40-44$ & $45-49$ & $50-54$ & $55-59$ & $60-64$ & $65-69$ & $70-74$ & $475+$ & - AAR & CR \\
\hline $\mathrm{C} 00$ & Lip & 6 & 0.0 & 0.0 & 0.0 & 0.0 & 0.0 & 0.0 & 0.0 & 0.0 & 0.0 & 0.0 & 0.0 & 0.0 & 0.1 & 0.1 & 0.1 & 0.1 & 0.4 & 0.2 \\
\hline C01-02 & Tongue & 180 & 0.0 & 0.0 & 0.0 & 0.0 & 0.0 & 0.1 & 0.1 & 0.1 & 0.7 & 0.6 & 1.3 & 1.2 & 1.7 & 1.7 & 1.1 & 0.7 & 9.4 & 7.0 \\
\hline C03-06 & Mouth & 147 & 0.0 & 0.0 & 0.0 & 0.0 & 0.0 & 0.0 & 0.1 & 0.1 & 0.5 & 0.5 & 0.6 & 1.3 & 1.7 & 1.6 & 0.7 & 1.0 & 8.0 & 5.7 \\
\hline C07-08 & Salivary Gland & 10 & 0.0 & 0.0 & 0.0 & 0.0 & 0.0 & 0.0 & 0.0 & 0.0 & 0.0 & 0.0 & 0.1 & 0.1 & 0.0 & 0.0 & 0.1 & 0.2 & 0.6 & 0.4 \\
\hline $\mathrm{C} 09$ & Tonsil & 117 & 0.0 & 0.0 & 0.0 & 0.0 & 0.0 & 0.0 & 0.0 & 0.1 & 0.4 & 0.6 & 0.7 & 1.2 & 0.7 & 0.7 & 1.0 & 0.7 & 6.1 & 4.5 \\
\hline $\mathrm{C} 10$ & Oth. Orpharynx & $\times \quad 75$ & 0.0 & 0.0 & 0.0 & 0.0 & 0.0 & 0.0 & 0.0 & 0.0 & 0.1 & 0.5 & 0.5 & 0.4 & 0.7 & 0.7 & 0.6 & 0.6 & 4.2 & 2.9 \\
\hline C11 & Nasopharynx & 17 & 0.0 & 0.1 & 0.0 & 0.0 & 0.0 & 0.0 & 0.0 & 0.1 & 0.0 & 0.0 & 0.1 & 0.0 & 0.1 & 0.1 & 0.1 & 0.0 & 0.8 & 0.7 \\
\hline C12-13 & Hypopharynx & 268 & 0.0 & 0.0 & 0.0 & 0.0 & 0.0 & 0.0 & 0.0 & 0.3 & 0.8 & 1.1 & 2.0 & 1.9 & 2.4 & 1.9 & 2.3 & 1.6 & 14.3 & 10.4 \\
\hline C14 & Pharynx & 41 & 0.0 & 0.0 & 0.0 & 0.0 & 0.0 & 0.0 & 0.0 & 0.0 & 0.1 & 0.1 & 0.2 & 0.1 & 0.3 & 0.6 & 0.3 & 0.9 & 2.6 & 1.6 \\
\hline $\mathrm{C} 15$ & Oesophagus & 479 & 0.0 & 0.0 & 0.0 & 0.0 & 0.0 & 0.0 & 0.1 & 0.4 & 1.1 & 2.0 & 2.7 & 2.9 & 4.1 & 5.5 & 3.2 & 5.2 & 27.3 & 18.6 \\
\hline $\mathrm{C} 16$ & Stomach & 214 & 0.0 & 0.0 & 0.0 & 0.0 & 0.0 & 0.1 & 0.1 & 0.1 & 0.6 & 0.8 & 0.6 & 1.5 & 1.9 & 2.1 & 2.0 & 2.9 & 12.6 & 8.3 \\
\hline C30-31 & Nose, Sinuses & 11 & 0.0 & 0.0 & 0.0 & 0.0 & 0.1 & 0.0 & 0.0 & 0.0 & 0.0 & 0.1 & 0.1 & 0.0 & 0.1 & 0.0 & 0.0 & 0.0 & 0.4 & 0.4 \\
\hline C32 & Larynx & 138 & 0.0 & 0.0 & 0.0 & 0.0 & 0.0 & 0.0 & 0.0 & 0.1 & 0.3 & 0.4 & 0.9 & 0.7 & 1.4 & 1.4 & 1.3 & 1.6 & 8.1 & 5.4 \\
\hline ALL & SITES & 3198 & 1.2 & 0.6 & 0.4 & 0.6 & 1.0 & 1.6 & 1.7 & 2.8 & 7.3 & 11.7 & 16.1 & 19.5 & 28.0 & 31.0 & 24.4 & 31.81 & 179.4 & 124.3 \\
\hline
\end{tabular}

Table 2. Age Specific Incidence Rates, Age-Standaridzed Incidence Rates (Aars) and Average Annual Crude Incidence Rates (Crs) by Site Among Females in the Kamrup Urban District, 2008-2011

\begin{tabular}{|c|c|c|c|c|c|c|c|c|c|c|c|c|c|c|c|c|c|c|c|c|}
\hline \multirow[t]{2}{*}{ ICD-10 } & \multirow[t]{2}{*}{ Sites } & \multirow[t]{2}{*}{ Total } & \multicolumn{18}{|c|}{ Age (years) } \\
\hline & & & 00-04 & $5-9$ & $10-14$ & $15-19$ & $20-24$ & $25-29$ & $30-34$ & $35-39$ & $40-44$ & $45-49$ & $50-54$ & $55-59$ & $60-64$ & $65-69$ & $70-74$ & $75+$ & AAR & CR \\
\hline $\mathrm{CO0}$ & Lip & 9 & 0.0 & 0.0 & 0.0 & 0.0 & 0.0 & 0.0 & 0.0 & 0.0 & 0.0 & 0.0 & 0.1 & 0.1 & 0.1 & 0.1 & 0.1 & 0.1 & 0.6 & 0.4 \\
\hline $\mathrm{C} 01-02$ & Tongue & 49 & 0.0 & 0.0 & 0.0 & 0.0 & 0.0 & 0.0 & 0.1 & 0.0 & 0.3 & 0.4 & 0.3 & 0.7 & 0.1 & 0.3 & 0.3 & 0.7 & 3.2 & 2.1 \\
\hline C03-06 & Mouth & 96 & 0.0 & 0.0 & 0.0 & 0.0 & 0.1 & 0.1 & 0.1 & 0.1 & 0.2 & 0.3 & 0.4 & 0.9 & 0.9 & 1.3 & 1.4 & 0.9 & 6.8 & 4.2 \\
\hline C07-08 & Salivary Gland & 10 & 0.0 & 0.0 & 0.0 & 0.0 & 0.0 & 0.0 & 0.0 & 0.0 & 0.0 & 0.1 & 0.1 & 0.0 & 0.2 & 0.2 & 0.0 & 0.0 & 0.6 & 0.4 \\
\hline C09 & Tonsil & 30 & 0.0 & 0.0 & 0.0 & 0.0 & 0.0 & 0.0 & 0.0 & 0.0 & 0.1 & 0.1 & 0.2 & 0.2 & 0.5 & 0.7 & 0.3 & 0.1 & 2.2 & 1.3 \\
\hline $\mathrm{C} 10$ & Oth. Orpharynx & 18 & 0.0 & 0.0 & 0.0 & 0.0 & 0.0 & 0.0 & 0.0 & 0.0 & 0.0 & 0.2 & 0.1 & 0.3 & 0.3 & 0.2 & 0.1 & 0.1 & 1.3 & 0.8 \\
\hline C11 & Nasopharynx & 9 & 0.0 & 0.0 & 0.0 & 0.0 & 0.0 & 0.0 & 0.0 & 0.0 & 0.0 & 0.1 & 0.1 & 0.0 & 0.1 & 0.1 & 0.0 & 0.1 & 0.5 & 0.4 \\
\hline C12-13 & Hypopharynx & 47 & 0.0 & 0.0 & 0.0 & 0.0 & 0.0 & 0.0 & 0.1 & 0.1 & 0.1 & 0.2 & 0.4 & 0.9 & 0.3 & 0.3 & 0.5 & 0.4 & 3.2 & 2.1 \\
\hline C14 & Pharynx & 12 & 0.0 & 0.0 & 0.0 & 0.0 & 0.0 & 0.0 & 0.0 & 0.0 & 0.0 & 0.1 & 0.1 & 0.1 & 0.2 & 0.1 & 0.2 & 0.1 & 0.8 & 0.5 \\
\hline C15 & Oesophagus & 263 & 0.0 & 0.0 & 0.0 & 0.0 & 0.0 & 0.0 & 0.1 & 0.2 & 0.8 & 1.5 & 1.9 & 3.1 & 3.7 & 2.8 & 2.8 & 1.8 & 18.6 & 11.5 \\
\hline $\mathrm{C} 16$ & Stomach & 109 & 0.0 & 0.0 & 0.0 & 0.0 & 0.0 & 0.0 & 0.2 & 0.2 & 0.4 & 0.7 & 0.9 & 0.7 & 1.1 & 0.9 & 1.0 & 1.2 & 7.2 & 4.8 \\
\hline C30-31 & Nose, Sinuses & 1 & 0.0 & 0.0 & 0.0 & 0.0 & 0.0 & 0.0 & 0.0 & 0.0 & 0.0 & 0.0 & 0.0 & 0.0 & 0.0 & 0.0 & 0.0 & 0.0 & 0.0 & 0.0 \\
\hline C32 & Larynx & 17 & 0.0 & 0.0 & 0.0 & 0.0 & 0.0 & 0.0 & 0.0 & 0.1 & 0.0 & 0.1 & 0.1 & 0.1 & 0.1 & 0.2 & 0.1 & 0.3 & 1.1 & 0.7 \\
\hline \multicolumn{2}{|c|}{ ALL SITES } & 2440 & 0.8 & 0.4 & 0.3 & 0.7 & 0.9 & 1.5 & 2.9 & 5.1 & 9.9 & 16.1 & 16.4 & 20.2 & 23.3 & 19.9 & 18.7 & 16.8 & 153.8 & 106.9 \\
\hline
\end{tabular}

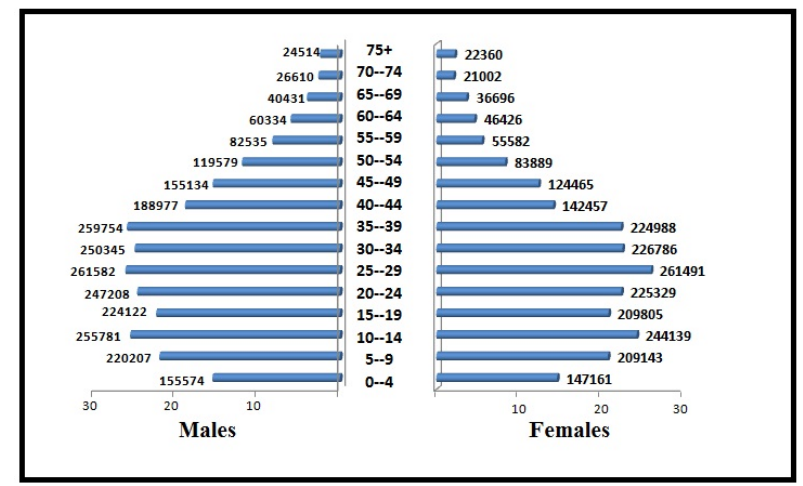

Figure 1.Population Pyramid Showing Age Distribution in the Kumrup Urban District During 2008-2011

The PBCR-Guwahati was established in 2003 at Dr. B. Borooah Cancer Institute, Guwahati-Assam, under National Cancer Registry Programme (NCRP), Indian Council of Medical Research (ICMR) and operating throughout with the objective to generate reliable Cancer data. Data on cancer of UADT cancers among KUD population were obtained for the period of 20082011. The Upper Aero-Digestive Tract (UADT) cancer groups consist of C00-C14, C30-C32, C15 and C16 was considered. Age-standardized or Age Adjusted rate (ASR or AAR) (per 100,000 person-years) was calculated using the World Standard Population as proposed by Segi (1960) and modified by Doll et al. (1966). The registry population area at risk was estimated using the 1991 and 2001 census population by sex, as well as the growth rate during that interval using the difference distribution method (Takair \& Shobana, 2009).

\section{Results}

There were a total of 5638 cases were registered during the last four years of the study (2008-2011) accounting a total of $56.7 \%(3198 / 5638)$ males and $43.3 \%(2440 / 5638)$ females (Table $1 \& 2$ ). The male : female ratio is 1.31 $: 1.00$. The estimated population at risk for five yearly age distribution for the period of 2008-2011 are shown in as population pyramid (Figure 1). The overall age adjusted rates (AAR) were 179.4 and 153.8 per 100,000 males and females respectively.

For Kamrup Urban District of NE India, in males a relative proportion of $53.3 \%(1703 / 3198)$ and in females $27.5 \%(670 / 2440)$ were UADT related cancers of total cancer cases. Among the UADT group carcinoma of Oesophagus was most common among the residents of KUD, accounting a total of $28.1 \%(479 / 1703)$ in males and $39.3 \%$ (263/670) in females followed by carcinoma of hypopharynx in males $15.7 \%$ (268/1703). Carcinoma of stomach is the third most common cancer sites among males of KUD with 12.6\% (214/1703) cases followed by carcinoma of tongue $10.6 \%(180 / 1703)$. Carcinoma of mouth is the fifth common cancer site in males $8.6 \%$ 
(147/1703) followed by $8.1 \%$ (138/1703). In Females carcinoma of stomach is the second most common site with $16.3 \%$ (109/670) of cases among UADT cancers followed by carcinoma of mouth $14.3 \%(96 / 670)$ and carcinoma of tongue $7.3 \%$ (49/670). Carcinoma of hypopharynx was the fifth most common cancer site among females with $7.0 \%$ (47/670) cases.

Oesophagus was found to be the leading incidence site among UADT cancer groups for both male and female with age adjusted incidence rate (AAR) 27.3, 18.6 respectively. Carcinoma of Hypo pharynx was the second most occurring site among male with AAR 14.3 followed by Stomach AAR 12.6. Carcinoma of tongue is the fourth most leading site among males with AAR 9.4 followed by Larynx in males with AAR 8.1. In female the second most leading site among UADT cancers is Stomach with AAR 7.2 followed by carcinoma of Mouth AAR 6.8. The fourth leading site among females was carcinoma of tongue with AAR 3.2 followed by carcinoma of Tonsil in females with AAR 2.2, while carcinoma of lip and Salivary gland are the least common site in both males (AAR 0.4,0.6) and females (AAR 0.6).

\section{Discussion}

According to recent report of NCRP, 2013 the PBCRs in the North Eastern India have emerged as high incidence zones globally. As per the report in males $50.5 \%$ and $24.7 \%$ in female cancer cases were UADT groups of cancer. The UADT group of cancer in Kamrup Urban District is more than national figure of India accounting a total of $53.3 \%$ in males and $27.5 \%$ in females.

Carcinoma of oesophagus is the top leading cancer site both for males and females among North Eastern regions of India. Esophageal cancer ranks as the sixth most common cancer among males and ninth most common cancer among females globally (Kumar et al., 2006). In East Khasi Hills it was observed that 323 (34.2\%) out of total 944 in male cases and in female 140 (24.9\%) out of total 563 female cancer cases were Oesophagus cancer cases for 2010-2011 period (NCRP 2013). While for the period of 2008 to 2011 in Kamrup Urban Distrcit is it observed that $479(15 \%)$ out of total 3198 male cases for all sites and in female $263(10.8 \%)$ out of total 2440 reported cases were of Oesophagus cancer. For the study period 2008-2011 in kamrup Urban District also observed that the incidence pattern of oesophagus cancer for both male \& female (AAR 27.3, 18.6) is much higher compared to most of the national regions and only lower some PBCRs of North East India followed as East Khasi Hills (AAR 71.4,30.2) and Meghalaya (AAR 46.2, 19.8). The high incidence of carcinoma of oesophagus may be due to the dietry habits, high amount of smoking, tobacco consumption and may be due to some of ethnic food habits like kolakhar as found one of the risk factors associated with it (Phukan et al., 2001; Rai et al., 2012; Sharma et al., 2014).

Carcinoma of Hypopharynx is continuously increasing in both males and females of North Eastern region of India. An estimated of total 19397 number of hypopharynx cancer cases was reported in 2010 while estimated projection is 22568 number of cases by 2020 (Takair et al., 2011). For Kamrup Urban District a total of 315 cases reported for the period of 2008-2011 accounting a total of $8.4 \%(268 / 3198)$ male cases and $1.93 \%$ (47/2440) numbers of female cases. The Age Adjusted Rate (AAR) in males was found as AAR 14.3 and in females AAR 3.2. As the observed Age Adjusted Rate (AAR) compared with NCRP report 2009-2011 (NCRP 2013) it is observed that in males KUD secures the third most carcinoma of hypopharynx prone area nationally while among females remains the top most hypopharynx prone area nationally. The rate of high incidence of oesophagus cancer may be due to habits of chewing of betel nut and tobacco consumption (Sharma et al., 2013).

Carcinoma of stomach is the third most common UADT group of cancers in males while second most among females of KUD. A total of 323 numbers of total cases with $6.7 \%(214 / 3198)$ in males and $4.47 \%$ $(109 / 2440)$ in females were stomach cancers to total cancers of KUD region. The AAR is observed as 12.6 and 7.2 for male \& female respectively. Stomach cancer is more prevalent among North Eastern state in both males and females, Aizwal District as well as whole Mizoram state are the top leading regions around the world after some regions of Japan. The high incidence may be due to some of the unconventional food habits like smoked meat, smoked fish and also the habit of consumption of rice beer along with the smoked meat and fish and also studied have shown that genetic modification like p53 codon 72 polmorpism with tobacco and dietry habits influence the occurrences of stomach cancer in these region (Krishnatreya et al., 2014; Malakar et al., 2014).

The fourth most common cancer in both males \& females carcinoma of tongue of UADT group of cancer. A total of 180 male cases and 49 female cases were reported during 2008-2011 period. The Age Adjusted Incidence Rate (AAR) for male and female were calculated as AAR 9.4 and 3.2 respectively. The carcinoma of tongue is at high among both males and females of this region, In comparison to national scenario with the NCRP report (2013) observed that KUD is the top most tongue cancer prone area among female nationally, while second most amongst males.

Carcinoma of mouth is the fifth common most site among males and third most among females with AAR 8.0 and 6.8 respectively. A total of 229 cases comprised of 180 males and 49 number of females were reported for 2008-2011 study period. Chewing of betel nut with or with-out tobacco, smoking are some of the common causes of mouth \& tongue cancer (Tarakanti et al., 2013; Mishra et al., 2014).

As from the study it is revealed that more than half of the cancer cases in males i.e. $53.3 \%$ and $27.5 \%$ among female were the UADT group of cancers to the total reported cancers for the period 2008-2011. As these cancers are mostly associated with risk factors like tobacco, betel nut, smoking, ethnic food \& dietry habits (as for example kolakhar risk factor of oesophagus cancer, tuibur, mozail etc. risk factor of stomach cancer), So this UADT group of cancers are preventable with adequate knowledge of risk factor association so a broad range of 


\section{Jagannath Dev Sharma et al}

investigation was needed. Also necessary tobacco control measures, awareness, campaign and association of ethnic food habits with occurrences of cancer should be brought into highlights among the communities.

In conclusion. UADT groups of cancers are highly increasing in this region and as most of them are preventable; controlling measures such as awareness camp, educating people about the known risk factors are needed to gear up. Also a depth research work would necessary to find out new potential risk factors associated with this group of cancers to control the high incidence pattern in this geographical region North East India.

\section{Acknowledgements}

We are thankful to Dr. A. Nandakumar, Deputy Director General, ICMR and Officer in charge of the National cancer Registry Programme of India for providing technical support and guidance. The authors are also thankful to Mr. Kamal C. Deka and to all the staff of Dr. B. Borooah Cancer Institute for their kind co-operation in different areas.

\section{References}

Anantharaman D, Chabrier AL, Gaborieau VR, et al (2014). Genetic variants in nicotine addiction and alcohol metabolism genes, oral cancer risk and the propensity to smoke and drink alcohol: a replication study in india. Plos One, 9, 1-7.

Doll R, Payne P, Waterhouse JAH, et al (1966). Cancer incidence in five continents. vol i. geneva: union internationale contre le cancer, Berlin, Springer.

Jemal A, Bray F, Center MM, et al (2011). Global cancer statistics. Ca Cancer J Clin, 61, 69-90.

Krishnatreya M, Gogoi G, Sharma JD, Kataki AC (2014). Patterns of cancer in select ethnic groups from assam: a retrospective study. Int Res J. Social Sci, 3, 17-20.

Kumar A, Chatopadhyay T, Raziuddin T, Ralhan R (2006). Discovery of deregulation of zinc homeostasis and its associated genes in esophageal squamous cell carcinoma using cDNA microarray. Int. J. Cancer, 120, 230-42.

Malakar M, Devi KR, Phukan RK, et al (2014). p53 Codon 72 polymorphism interactions with dietary and tobacco related habits and risk of stomach cancer in Mizoram, India. Asian Pac J Cancer Prev, 15, 717-23.

Mishra A, Meherotra R (2014). Head and neck cancer: global burden and regional trends in India. Asian Pac J Cancer Prev, 15, 537-50.

Oze I, Matsuo K, Suzuki T, et al (2009). Impact of multiple alcohol dehydrogenase gene polymorphisms on risk of upper aerodigestive tract cancers in a japanese population. Cancer Epidemiol Biomarkers Prev, 18, 3097-102.

Phukan RK, Chetia CK, Ali MS, Mahanta J (2001). Role of dietary habits in the development of oesophageal cancer in assam, the north-eastern region of india. Nutr Cancer, 39, 204-9.

Rai AK, Freddy AJ, Banerjee A, et al (2012). Distinct involvement of 9p21-24 and 13q14.1-14.3 chromosomal regions in raw betel-nut induced esophageal cancers in the state of Meghalaya, India. Asian Pac J Cancer Prev, 13, 2629-33.

Segi M (1960). Cancer mortality for selected sites in 24 countries (1950-57). sendai, japan: department of public health, Tohoku University of Medicine.
Sharma JD, Kataki AC, Vijay CR (2013). Population based incidence and patterns of cancer in kamrup urban cancer registry. India Natl Med J India, 26, 133-41.

Sharma JD, Kalita M, Nirmolia T et al (2014). Cancer: scenario and relationship of different geographical areas of the globe with special reference to north east-india. Asian Pac J Cancer Prev, 15, 3721-9.

Sharpe HK, McMahon AD, Raab GM, Brewster DH, Conway DI (2014). Association between socioeconomic factors and cancer risk: a population cohort study in Scotland (19912006). Plos One, 9, 1-15.

Takiar R, Shobana B (2009). Cancer incidence rates and the problem of denominators-a new approach in Indian cancer registries. Asian Pac J Cancer Prev, 10, 123-6.

Takiar R, Nadayil D, Nandakumar A (2010). Projections of number of cancer cases in india (2010-2020) by cancer groups. Asian Pac J Cancer Prev, 11, 1045-9.

Taranikanti M \& Das B (2013). Risk factor profile of oral cancer patients in North East India. IJBR, 04, 615-622.

NCRP (2013). Three year report of Population Based Cancer Registries 2009-2011. National Cancer Registry Programme (ICMR), National Centre for Disease Informatics \& Research (NCDIR). 